\title{
Principles and perils of silviculture audits ${ }^{1}$
}

\author{
by Jordan S. Tanz ${ }^{2}$ and W.L. Craig Campbell ${ }^{3}$
}

Forestry audits may be used as a means of assuring the public that forestry practices are meeting accepted standards, as part of an internal monitoring system, or as part of efforts to resolve disputes with outside interest groups. In this paper, silviculture auditing is examined with specific reference made to the situation in British Columbia. Well-established principles of financial auditing are used as the basis for a framework of principles for silviculture auditing. Ways in which these principles can be applied in practice are shown. Some of the problems with undertaking silviculture audits are briefly reviewed.

\section{Introduction}

Auditing is an unusual topic for a gathering of foresters. We are not well-known for our fondness for the details of financial accounting. Although auditing is not sexy, it is attracting our attention. Neither is it particularly fun, but we are being forced to play. Finally, auditing is not well understood in the forestry context, but it is, nevertheless, becoming more and more important.

In 1986, Gordon Baskerville undertook "An Audit of Management of the Crown Forests of Ontario" (1986) at the request of the Minister of Natural Resources. Since then, interest in auditing forestry activities has increased. In 1991 the Auditor General of British Columbia, as part of its regular investigations of all significant operations of government, found that the Ministry of Forests' "...monitoring practices do not give adequate assurance that major licensees are meeting their reforestation responsibilities." More recently, the Minister of Forests castigated the forest industry for apparent violations of harvesting regulations as revealed in an audit of watercourses on Vancouver Island. When the subject of forestry comes up today, the word "audit" frequently follows close behind.

To motivate this discussion, let us examine why one might want to audit silviculture activities. In British Columbia, the reforestation responsibilities of a major licensee are defined in the Forest Act, the Silviculture Regulation, and the pre-harvest silviculture prescription, or PHSP, for each cutting permit. Therefore, the objective of any silviculture audit program undertaken by the Ministry of Forests might be to provide information about the extent to which licensees are fulfilling their obligations as defined in these documents.

A company might have different reasons for undertaking silviculture audits. It might want to use audits as part of an

\footnotetext{
${ }^{1}$ Presented at CIF-IFC Annual Meeting, Sept. 20-24, 1992, Vancouver, British Columbia.

${ }^{2}$ Cortex Consultants Inc., 201-1290 Broad Street, Victoria, British Columbia, Canada V8W 2A5.

${ }^{3}$ Senior Manager, Price Waterhouse, 601 West Hastings Street, Vancouver, British Columbia, Canada V6B 5A5.
}

Les vérifications en foresterie peuvent être utilisées comme moyen d'assurer le public que les pratiques forestières utilisées sont conformes aux normes établies, soit en tant qu'élément du système de surveillance interne, soit en tant que l'une des solutions adoptées pour résoudre les disputes avec les groupes de pression. Dans cet article, la vérification en sylviculture est abordée dans le contexte spécifique de la situation vécue en Colombie-Britannique. Les principes reconnus de la vérification financière sont utilisés comme base du cadre de travail des principes de la vérification en sylviculture. La façon d'appliquer ces principes dans la pratique est illustrée. Quelques-uns des problèmes découlant de la mise en place de vérifications en sylvicultures sont brièvement abordés. internal system of monitoring company activities to help improve the quality of management decisions by providing accurate, unbiased and current information. The company may also want to report audit results to company employees, directors, shareholders, or other stakeholders interested in the operations of the organization. In some situations it may be necessary to have an assessment of silviculture activities as part of efforts to resolve disputes with outside groups interested in the way lands are managed by the company. Finally, the company might want an internal audit system designed to reveal potential problems before they are reported by an external audit.

Audits frequently play an important role as part of a larger system for regulating the activities of organizations. For example, in BC, the Ministry of Forests does not directly monitor the silviculture activities of major licensees. Instead, the Ministry uses a system of controls (the PHSPs), reporting requirements (Major Licensee Silviculture Information System) and silviculture audits to ensure that the obligations of major licensees are met. These three components - controls, reporting requirements and audits - are like the three legs of a stool on which the Ministry's system for regulating silviculture performance rests (Fig. 1). If any one of the three is inadequate, the system topples. One must recognize the importance of each of the three elements in this management system to understand the underlying importance of auditing.

Auditing has other values as well. It adds value to licensee and Ministry reporting firstly because it is likely that reports will be more carefully prepared if it is known that they may be audited, and secondly because it provides reasonable assurance that inaccuracies will be discovered. However, for the audit to add such value to other controls, the auditor must be at arm's length from the organization being audited. We will return to this topic later.

\section{Auditing Theory}

In our efforts to develop a defensible framework for silviculture auditing, we turned to financial auditing for principles which could be applied in the forestry context, beginning with the basic elements for silviculture. 


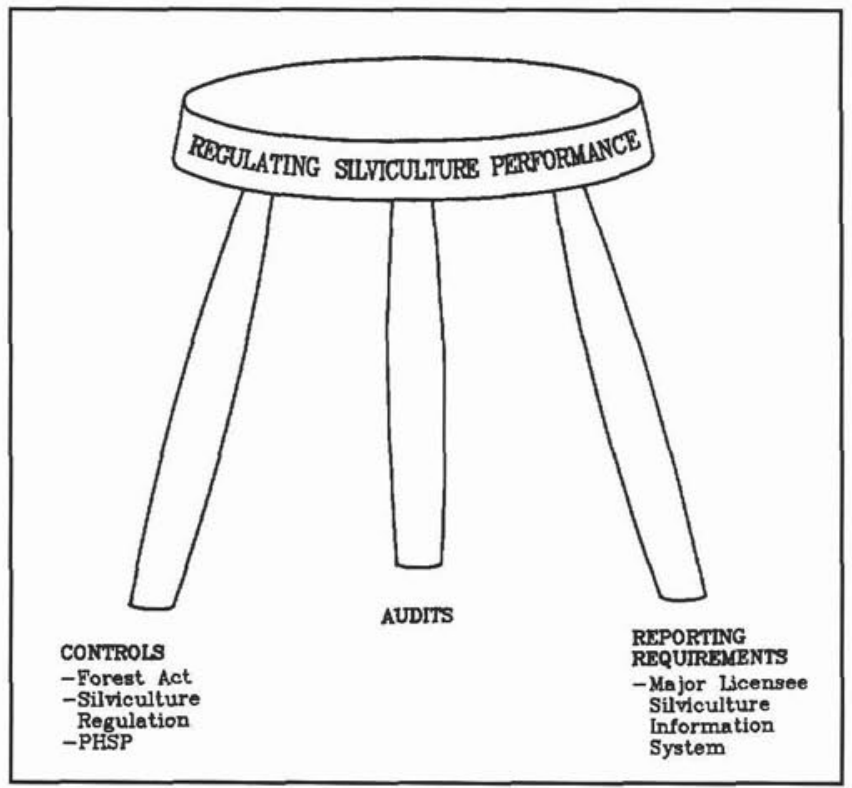

Figure 1. The three legs of the stool supporting the B.C. Ministry of Forests system for regulating silviculture performance.

An audit is a process for determining the degree of correspondence between what actually happened and what was reported or expected. It is an objective assessment, designed to serve the information needs of interested parties who may not have access to the activities or internal workings of the organization. An audit is a procedure that involves achieving audit objectives by applying certain audit techniques to different types of audit evidence.

\section{Audit objectives}

The objectives of silviculture audits can be expressed in the following statement paraphrased from a financial auditing textbook: to express, on the basis of sufficient appropriate evidence, an objective opinion as to whether the auditee's statements and reports present fairly the position and results of operations of the auditee in accordance with generally accepted accounting principles applied on a consistent basis (Anderson 1984).

These objectives of auditing can be met by the verification of two types of assertions. Verification of substantive assertions confirms the existence or completeness of something. For instance, was a cutblock treated as prescribed or claimed? Was the treatment applied to the whole block? Were survey results reported accurately and completely?

Verification of compliance assertions is a little different. It refers to controls, and specifically to confirming the existence of controls, to assessing the effectiveness of controls, and to checking the continuity of controls. For example, are there appropriate standards for regeneration surveys? Do these standards ensure that surveys are executed properly? Are the standards always used?

In the absence of adequate internal control standards, the audit objectives are met by the verification of substantive assertions. The need for such detailed testing is reduced as the organization provides better controls. Convince the auditor that there is a system in place that verifies what has taken place and he will be willing to accept your claims without seeing it all himself.

Generally, the auditor seeks evidence concerning both of these auditing assertions, and for good reason. Confirming the existence of controls such as a system of formal planting quality checks does not compensate for their discontinuous or inconsistent use. Obtaining evidence that a treatment was performed will not compensate for failing to establish that it was done to an appropriate level of quality.

\section{Audit Evidence}

Audit evidence is any object, action, or condition relevant to the formation of a knowledgeable opinion on the silviculture activities of the organization. Silviculture auditing would be simple if audit resources were unlimited. One would simply need to visit and survey every individual block managed by a licensee to determine the extent to which the licensee has met its obligations. Unfortunately, audit resources are not unlimited, and the auditor is forced to find an acceptable compromise balancing accuracy, precision, risk and economy in determining what types of audit evidence and technique to use. Further, the choice of audit technique depends to a great degree on the type of evidence required.

Audit evidence can be classified according to its source:

- Direct personal knowledge of auditor

- External evidence (from third parties)

- Internal evidence (from within the organization

- Overlapping evidence (different pieces of evidence) Which types and how much of each type of evidence should be gathered must be decided according to the perceived risk. Some of the factors that affect risk include:

(1) Required accuracy and precision. What is the maximum amount of error you are willing to accept?

(2) Required assurance, or the risk of failing to detect non-compliance, which in turn depends upon:

- Inherent risk, which is the risk that a block will fail to meet the standards at a specific stage. It may be related to the organization involved, silvicultural stage, silvicultural system or treatments used, biogeoclimatic zone/ecosystem, species, weather, or difficulty of access.

- Control risk, which is the risk of the control system failing to prevent or detect the error, depends upon the competence of management, suitability of the PHSP, competence and diligence in executing block surveys, methods used to compile survey data, cost of retreatment if failure detected (there may be some incentive for the organization to conceal a treatment failure if the cost of retreatment is very high).

- Audit risk, or the risk of the audit failing to detect the error, is dependent on sampling risk, competence and diligence of auditor.

(3) Reliability of evidence, or the credence that should be given to different types of evidence. In general terms:

- Direct personal knowledge of the auditor, gained through physical examination, observation of activities, or recomputation of post-treatment survey results is more reliable than evidence obtained indirectly (e.g. through inquiry).

- Evidence obtained through external or third party sources is more reliable than evidence obtained within the organization. 
- The existence of satisfactory controls signifies greater reliability of documentary evidence than there would be without satisfactory controls. For instance, if the auditor is able to determine that a licensee has diligently and accurately reported its silvicultural activities, then these reports would be considered to be a much more reliable source of audit evidence than if such were not the case.

Thus, an actual auditor's visit to a block would provide the most reliable evidence that it had been scarified, but failing that, written confirmation from the contractor who did the work for the client organization would be more reliable than confirmation from the organization itself. Evidence of a strong system of quality control would give greater credence to claims for satisfactory implementation of treatments than such claims would have without the evidence of quality control.

(4) Sufficiency of evidence. How much evidence is required to justify the formation of an opinion as to the audit objectives? Each additional piece of evidence pointing toward the same conclusion does lend credence to that conclusion. Although the auditor could examine every single piece of evidence, if the population of cutblocks is very large for instance, an opinion could be justified long before the last cutblock has been visited and resurveyed. If sampling is done objectively and systematically, a sample drawn from a larger population can provide adequate assurance as to the opinion formed.

(5) Timeliness and economy. The auditor must weigh the costs of obtaining additional assurance that the audit opinion is justified against the value of that additional assurance. The audits must be completed with the resources available.

\section{Audit Technique}

Silviculture auditing does not necessarily require or imply that a specific proportion of a licensee's cutting permits or blocks must be visited by the auditor. The auditor has an array of techniques which can be used to accomplish different audit objectives. Exactly which techniques are used will depend on the type and amount of evidence necessary to form an audit opinion, which in turn may be a function of numerous factors including the size of operations, past performance, the characteristics of the blocks and users of the report, and the potential losses as compared with the cost of the audit techniques.

Silvicultural auditing techniques include the following:

(1) Physical examination of cutblocks. By actually travelling to the block, the auditor can verify that a treatment was implemented (i.e., the block was actually planted) and that the treatment was complete (the whole block was planted). Physical examination is a direct source of evidence, and as such is very reliable, but can answer only a limited set of questions. For instance, a simple walkthrough or flight over the block cannot be used to determine whether or not the treatment standards were met. For this purpose, other techniques must be used, as described below.

(2) Reperformance of survey or calculation routine. Reperformance refers to the practice of repeating a procedure to verify that it was done correctly and that results were reported accurately. It may be necessary for the auditor to survey (or employ a contractor to survey) a block to provide adequate assurance that standards are being met. If the auditor finds that the reperformance results match those of the original survey, the results of other surveys can be given greater credence. On the other hand, finding that surveys undertaken by the licensee are suspect reduces the credence that should be given to the survey results for other blocks.

(3) Observation of survey crews. By observing the practices of a crew in the process of surveying a block after treatment, the auditor may obtain strong evidence that treatment standards have been met when associated with survey results about other blocks. However, the auditor still must determine whether or not this type of control (post-treatment survey) has been used continuously and consistently on all blocks.

(4) Vouching. Vouching is the verification of an event by close examination of source documents such as survey notes and plot records. It serves substantive objectives by providing evidence that the event actually occurred. For instance, in the case of a regeneration survey used to determine that stocking standards were met, vouching verifies that a survey was really done, that it was done correctly, and that the results of the survey were calculated correctly. Except for the possibility that the entire set of survey notes and plot records were falsified, it provides very strong evidence for formation of an audit opinion about the degree to which the regeneration delay standards were met.

(5) Enquiry about unusual items. An astute auditor will look for unusual items in the evidence available. For instance, in the example of the regeneration survey given above, if the field notes were inordinately clean and neat, the auditor might conclude that either they had been copied onto fresh sheets in the office because they were illegible, or they had been falsified. He might then follow up with inquiries about office procedures for instance, to determine if it was regular procedure to copy out field notes.

\section{Types of Audit Testing}

Audit testing refers to the method used to choose items for examination. Testing methods can be categorized as one of three types:

- High-importance item selection

- Key item selection

- Representative selection.

High-importance selection refers to the method of weighting sample units by importance, e.g. block size. Such an approach may be desirable in situations where most of the area harvested by a licensee was in a small number of very large blocks. In situations where blocks are uniform in size, this method would be inappropriate.

Key item selection involves the selection of blocks that are considered to be problematic for one reason or another. For instance, they might be in an ecosystem type that is particularly difficult to reforest, or might have been planted in a particularly dry year. The common practice of "targeting" suspect blocks for examination falls in this category. 
Representative or random selection involves choosing blocks at random from the entire population, or from within pre-defined strata, and according to the accepted methods for statistical sampling.

\section{Assumptions of Auditing}

Auditing practice is based on certain assumptions about evidence and technique. In the absence of indications to the contrary:

- External evidence is more reliable than internal evidence

- Direct personal knowledge is more reliable than indirect evidence

- Good internal control reduces the probability of errors

- Past errors increase the probability of current errors

- Absence of past errors reduces the probability of current errors

- In the absence of suspicious circumstances, we can assume that no special effort need be expended to detect fraud, forgery of documents, or management conspiracy to deceive the auditor

- In the presence of reasonable controls, it is often more efficient to verify the functioning of the control system and rely on it, than it is to perform the substantive tests necessary when no reliance is made.

\section{Choice of Audit Technique}

Five different audit techniques have been described: physical examination, reperformance, observation, vouching, and enquiry. It is evident that the auditor need not be restricted to using physical examination, i.e., visiting cutblocks. In fact, unless it is coupled with the use of another technique, physical examination has only limited usefulness in the systematic, objective gathering of audit evidence.

Consider for instance, the amount of useful audit information that can be gathered by simply walking through a block. This procedure can be used to determine that a treatment was or was not actually implemented. But without a statistically valid survey, can any conclusions be drawn, for example, about the completeness of the treatment, or about the quality of its application? What legitimate or legal claims can be made upon the licensee after only a simple walk through the block?

The auditor must consider the objectives of the audit and the types of evidence required to meet those objectives when choosing which audit techniques to employ in any situation. Frequently it will be found that a combination of many of the techniques described above is the best approach.

\section{The Perils of Silviculture Auditing} lurk:
Biting the hand that feeds you. For the auditor, there is always the danger of alienating the client if the audit reveals failings on the client's part. While every consultant is alert to the dangers of biting the hand that feeds him, the auditor must ensure that his or her objectivity prevails. It is of utmost importance that the auditor be seen to be at arm's length from the auditee.

Challenge/refutation of audit results. Foresters operate in a hostile environment today; we are likely to be challenged about almost anything we do in the field, and auditors of forestry activities are as likely to be challenged as any of us. If their work is to be defensible, auditors must be working at arm's length from both the government and licensees, and the audit must follow accepted principles and practises.

Failing to reach conclusive audit results. Auditing requires both technical expertise in sampling, and sound professional understanding and judgement about the business under audit. When it is over, the auditor has to be able to sign off by either supporting or refuting the claims of the organization under audit. It is all too easy to execute an audit that can't provide definitive answers.

\section{Conclusions}

Before embarking on a program to audit silviculture operations or performance, organizations should carefully consider some important points. First, different types of audit evidence may be acceptable for accomplishing the objectives of a silviculture audit program. Determine which ones are appropriate for your program.

Different techniques for gathering audit evidence should be evaluated. These could include physical examination of cutblocks, reperformance of surveys or survey calculations, observation of survey crews, vouching of field notes, and enquiry about unusual items. A combination of different techniques will frequently be the most effective approach.

Different types of audit testing may be used, but exactly which ones are chosen in any particular audit will depend on the characteristics of the situation. Some type of representative or random selection from a stratified population may be the most effective method in many situations.

The auditor should be at arm's length from the organization, be it major licensee, or a government agency.

The audit program will require appropriate training for auditors if it is to be effective. Among other things, the auditor must be an experienced and knowledgeable field forester, must be reasonably sceptical, and must be very familiar with the range of techniques available to him or her.

\section{References}

Anderson, R.J. 1984. The external audit, 2nd edition. Copp Clark Pitman, Toronto.

Baskerville, G.L. 1986. An audit of management of the Crown forests of Ontario. Province of Ontario. 